\title{
Economic impact of biologic utilization patterns in patients with psoriatic arthritis
}

\author{
Sergio Schwartzman ${ }^{1} \cdot$ Yunfeng $\mathrm{Li}^{2} \cdot$ Huanxue $\mathrm{Zhou}^{3} \cdot$ Jacqueline B. Palmer $^{2}$
}

Received: 17 January 2017 /Revised: 10 April 2017 / Accepted: 13 April 2017 / Published online: 4 May 2017

(C) The Author(s) 2017. This article is an open access publication

\begin{abstract}
The aim of the study is to examine the frequency and costs associated with above-label dosing of biologics in patients with psoriatic arthritis (PsA). MarketScan identified adults with $\geq 1$ International Classification of Diseases, Clinical Modification diagnosis for PsA and $\geq 1$ pharmacy claim for biologics of interest between January 1, 2011 and December 31, 2013. The first biologic claim was the index date with a 1-year follow-up period and three additional months to confirm continuous biologic use. Exclusion criteria included switching to a different biologic or diagnosis with another autoimmune disease. During the follow-up period, duration was stratified into three groups: $<30,30-179$, and $\geq 180$ days of above-label dosing ( $>10 \%$ of the labeled dose). One-tailed $t$ test was conducted to examine the impact of above-label duration on healthcare costs. We identified 4245 PsA patients receiving etanercept $(n=2342)$, adalimumab $(n=1788)$, and golimumab $(n=115)$. Above-label dosing of $<30$ days ( $85 \%$ adalimumab, $90.4 \%$ etanercept, and $95.7 \%$ golimumab) and $\geq 180$ days (9.6\% adalimumab, $4.1 \%$ etanercept, and $2.6 \%$ golimumab) was observed. All-cause total healthcare costs for $<30$ days of above-label use (etanercept $\$ 30,625$, adalimumab $\$ 31,620$, and golimumab $\$ 37,224$ ), 30-179 days (etanercept $\$ 35,602$, adalimumab $\$ 38,915$, and golimumab $\$ 64,349$ ), and $\geq 180$ days (etanercept $\$ 55,349$, adalimumab $\$ 54,176$, and golimumab $\$ 47,993$ ) were reported. Longer above-label duration (30-179 versus
\end{abstract}

Sergio Schwartzman

schwartzmanS@hss.edu

1 The Hospital for Special Surgery, 535 E 70th St, New York, NY 10021, USA

2 Novartis Pharmaceuticals Corporation, East Hanover, NJ, USA

3 KMK Consulting Inc., Morristown, NJ, USA
$<30$ days, $\geq 180$ versus $30-179$ and $\geq 180$ days) with etanercept or adalimumab was significantly associated with higher mean increased total all-cause healthcare, PsAspecific healthcare, and biologic costs $(p<0.05)$. Abovelabel use of anti-TNF biologics does occur and is associated with significantly increased healthcare costs.

Keywords Above-label dosing · Disease-modifying antirheumatic drug $\cdot$ Dose escalation $\cdot$ Drug costs $\cdot$ Psoriatic arthritis

\section{Introduction}

Psoriatic arthritis (PsA) is a chronic disease which requires aggressive and continuous treatment to manage symptoms and prevent disability [1]. Biologic disease-modifying antirheumatic drugs (bDMARDs, also referred to as biologics) are currently recommended for patients with PsA [2,3]. A lack of PsA symptom control with initial bDMARD use has been reported to influence decisions to change medications or request additional treatment options [1,3-7]. Traditionally in a non-responder, a physician may switch the patient from one bDMARD to another bDMARD or change the dose of the therapy being utilized [3-8]. Treat-to-target strategies are also being recommended as a patient-centric approach for managing PsA. Minimal disease activity criteria have been developed to provide targets for tailoring treatments according to patient needs $[9,10]$. A recent clinical trial examined a treatto-target approach and reported statistically significant improvements in both disease activity as well as patientreported outcomes without any unexpected safety concerns [11].

Recent studies have shown that optimizing bDMARD therapy via off-label dosage for patients with rheumatic diseases is 
becoming more routine [12-14]. Limited research has been conducted to support long-term health outcomes associated with patterns of bDMARD utilization in the symptom management of PsA [3, 4, 12, 15, 16]. Off-label dosages (i.e., dose escalation or reduction, interrupted treatment) have been shown to occur in clinical practice for the treatment of other inflammatory conditions, such as psoriasis $(\mathrm{PsO})$ and rheumatoid arthritis (RA) [8, 13, 17-20]. Studies have demonstrated that dose escalation with bDMARDs commonly occurs for patients with RA and results in increased cost [13, 18-22]. Off-label dosage has also been examined in patients with $\mathrm{PsO}$, where dose escalation in non-responders generally resulted in increased efficacy with certain bDMARDs (etanercept, adalimumab, infliximab, ustekinumab, and alefacept) [17, 23].

An understanding of the economic implications of realworld medication utilization patterns to manage and control the symptoms of PsA is needed. bDMARDs are reported to be cost-effective for the treatment of moderate-to-severe PsA, mainly due to substantial improvement in decreasing disease activity, preventing radiographic progression, and improving functional status and quality of life [2, 24, 25]. A recent US commercial claims study reported that the annual costs associated with bDMARD treatment for PsA were $\$ \$ 26,916$, $\$ 27,987, \$ 28,749$, and $\$ 31,974$ (2015 US dollars) for etanercept, golimumab, adalimumab, and infliximab, respectively [26]. Annual direct medical costs for patients with PsA have been reported as $\$ 5108$ (\$22,258) (2012 US dollars, mean [SD]) [27]; however, to date, economic studies for PsA do not provide information on the cost of off-label treatment with patients on biologics and cost-effectiveness of offlabel dosing [2, 24, 25]. Due to the long-term nature of treating PsA, the costs of real-world medication utilization of bDMARDs can define treatment options for clinicians and formulary decision makers [28]. This study describes the patient demographics, medication utilization patterns, and associated total healthcare costs among patients with PsA receiving subcutaneous bDMARDs in a real-world setting in the USA.

\section{Materials and methods}

\section{Data source}

A retrospective administrative claims database analysis was conducted using Truven Health Analytics MarketScan ${ }^{\circledR}$ Commercial and Medicare Databases in the USA [29]. The MarketScan Commercial and Medicare Databases provide detailed cost, utilization, and outcome data for healthcare services performed in both inpatient and outpatient settings. Unique enrollee identifiers link medical claims to outpatient prescription drug claims and person-level enrollment data.
Database constructs include information on patient demographics (age, gender, employment status, and geographic location), healthcare utilization, costs (payment), and comprehensive prescription drug data $[29,30]$.

All study data were accessed using techniques compliant with the Health Insurance Portability and Accountability Act of 1996. No identifiable or protected health information was extracted during the course of the study; hence, the study did not require informed consent or institutional review board approval.

\section{Sample selection and patient population}

Adult PsA patients enrolled in the Truven Health MarketScan Commercial and Medicare Supplemental Claims Databases were identified between January 1, 2011 and December 31, 2013 (identification period) [29]. Patients' first bDMARD claim was the index date, followed by a 1-year follow-up period and an additional 3-month look-forward period to confirm continuous enrollment and biologic use. The study period ended March 31, 2015. Patients included in the study had $\geq 1$ International Classification of Disease, Ninth Revision, Clinical Modification (ICD-9-CM) claim for PsA (ICD-9CM code 696.0) 1 year before or at the date of first bDMARD use and $\geq 1$ pharmacy claim for etanercept, adalimumab, certolizumab, golimumab, and ustekinumab during the identification period. Intravenous bDMARDs were not evaluated due to limited dosing information in the claims database.

Patients were excluded from the study if they were $<18$ years of age and had switched to a different bDMARD (including infliximab) during the study period. Patients were also excluded if they had a diagnosis for any of the following diseases: ankylosing spondylitis (ICD-9-CM 720.0), RA (ICD-9-CM 714.x), juvenile idiopathic arthritis (ICD-9-CM 714.3), Crohn's disease (ICD-9-CM 555.x), ulcerative colitis (ICD-9-CM 556.x), and uveitis (ICD-9-CM 364.0) in order to confirm that the bDMARD treatment was for PsA. Those with human immunodeficiency virus, cancer, and tuberculosis were also excluded to ensure that drug was not discontinued due to a comorbidity.

\section{Treatment cohorts}

bDMARDs of interest were etanercept, adalimumab, certolizumab, golimumab, and ustekinumab. Patients who received certolizumab $(n=0)$ or ustekinumab $(n=14)$ were not included due to small sample size leaving only anti-TNF users in the study since the approvals for these medications were in late 2013. Treatment cohorts were established based on their corresponding index bDMARDs (i.e., etanercept, adalimumab, and golimumab). 


\section{Demographic and baseline patient characteristic variables}

Variables including patient demographics, clinical characteristics, and total all-cause healthcare costs (medical and pharmacy) were collected and evaluated for 1 year prior to the index date. Demographic variables of interest were age, gender, insurance type (fee for service (FFS) versus health maintenance organization and geographic region [northeast, north central, south, west, and unknown]). Clinical characteristics collected were concomitant use of non-biologic DMARDs (methotrexate, sulfasalazine, and leflunomide) and PsArelated comorbidities (e.g., PsO [ICD-9-CM 696.x], cardiovascular disease [ICD-9-CM 429.2, 413.x, 410.x, 425.x, 428.x, 430-438], hypertension [ICD-9-CM 401.x], hyperlipidemia [ICD-9-CM 272.x], type 2 diabetes [ICD-9-CM 250.x2], obesity [ICD-9-CM 278.xx], respiratory disease [ICD-9-CM 493.x, 491.x, 492.x, 496.0, 493.2x, 327.2x], gastrointestinal disease [ICD-9-CM 533.x, 564.1, 555.x, 556.x], neurological disorders [ICD-9-CM 356.8, 345.xx, 340.0], liver disease [ICD-9-CM 571.8, 573.3], autoimmune disease [ICD-9-CM 240.0-246.0, 579.0, 250.x1, 710.2, 710.0], depression [ICD-9-CM 300.4, 296.2, 296.3], anxiety [ICD-9CM 313.0, 300.0x], osteoporosis [ICD-9-CM 733.0], and fibromyalgia [ICD-9-CM 729.1]).

The Quan's Elixhauser comorbidity index (ECI) score was used to measure the burden of comorbid conditions not directly related to PsA. To differentiate 31 comorbid conditions from complications associated with the disease, ECI utilizes the ICD-9 codes of only the secondary diagnoses unrelated to the primary disease of interest, in this case PsA (i.e., PsA). The mean ECI score and proportion of patients reporting comorbidities for each condition were analyzed [31]. In addition, the Chronic Conditions Warehouse algorithm measured the occurrence of selected PsA-related comorbidities [31-33].

\section{Outcome measures}

The primary outcome for this study was above-label utilization of etanercept, adalimumab, and golimumab during the 1year follow-up period among patients with PsA. Daily dose for each patient was calculated as total dose of bDMARD for each refill divided by day supply; daily dose was classified into above-label, below-label, or on-label in comparison with labeled dose of each bDMARD. Labeled dosages in PsA for each biologic were as follows: $50 \mathrm{mg}$ once weekly for etanercept [34], $40 \mathrm{mg}$ every other week for adalimumab [35], and $50 \mathrm{mg}$ once a month for golimumab [36]. Within each treatment cohort, utilization included mean days of above-label, below-label, and on-label use (defined as dose $>10,<10$, and $\pm 10 \%$ of the labeled dose, respectively). Duration was stratified into three groups: those with minimal to no above-label use ( $<30$ days), 30-179 days of above-label use, and those with a significant amount of above-label use
( $\geq 180$ days) during the 1-year follow-up period. Patient demographics and total annual healthcare costs (pre-index and follow-up years) were captured.

\section{Data analysis}

Demographics and comorbidities for 1 year prior were compared for the etanercept, adalimumab, and golimumab cohorts. All continuous variables are presented as mean and standard deviation (SD). All categorical variables are presented as percentages or frequencies. The mean number of days above-label or below-label as well as the number of patients grouped by above-label duration $(<30,30-179$, and $\geq 180$ days) were tested for significance between treatment cohorts using the Wilcoxon Mann-Whitney test for continuous variables and the chi-squared test (the Fisher's exact test was employed when at least $20 \%$ of the cells had an expected value less than 5) for categorical/dummy variables.

All costs were converted to 2014 US dollars using the Medical Consumer Price Index. Total all-cause healthcare costs were normalized to annualized costs. A one-tailed $t$ test was conducted to examine the impact of the duration of above-label dosing (30-179 versus $<30$ days, $\geq 180$ versus $30-179$ days, and $\geq 180$ versus $<30$ days) on mean total healthcare costs (all-cause, PsA-specific, biologics, and nonbiologics) in the follow-up period. The incremental mean total healthcare cost in the post-index and pre-index periods were compared among above-label dosing groups (30-179 versus $<30$ days, $\geq 180$ versus $30-179$ days, and $\geq 180$ versus $<30$ days).

\section{Results}

\section{Baseline demographic characteristics}

The final study population included 4245 PsA patients: etanercept cohort $(n=2342)$, adalimumab cohort ( $n=1788)$, and golimumab cohort $(n=115)$ (Fig. 1).

Baseline demographics were similar across treatment groups. The majority of patients were males (etanercept [59.0\%], adalimumab [58.6\%], and golimumab [52.2\%]), with a mean age of approximately 50 years, predominately residing in the southern region of the USA with FFS health insurance. Most patients had at least one PsA-related comorbidity as well as multiple concomitant medications. The majority of PsA patients were treatment experienced, with etanercept showing the highest proportion of patients with prior biologic use $(67.0 \%)$, followed by golimumab $(57.0 \%)$ and adalimumab $(56.0 \%)$ (Table 1$)$.

PSA-related comorbidities were similar across the etanercept (74.8\%), adalimumab (77.2\%), and golimumab (70.4\%) cohorts. Hypertension (etanercept $28.7 \%$, 
Include patients who had index event ${ }^{\mathrm{a}}$ between January 1, 2011 and December 31, 2013

\begin{tabular}{|c|c|c|}
\hline $\begin{array}{l}\text { Etanercept } \\
(\mathrm{n}=82,000)\end{array}$ & $\begin{array}{l}\text { Adalimumab } \\
(n=90,239)\end{array}$ & $\begin{array}{l}\text { Golimumab } \\
(\mathrm{n}=7884)\end{array}$ \\
\hline$\downarrow$ & $\downarrow$ & $\downarrow$ \\
\hline \multicolumn{3}{|c|}{$\begin{array}{l}\text { Include patients who had continuous enrollment in medical and } \\
\text { pharmacy benefit from the start date of baseline period }{ }^{\mathrm{b}} \text { through } \\
\text { follow-up period }{ }^{\mathrm{c}} \text { to the end of look-forward period }\end{array}$} \\
\hline $\begin{array}{l}\text { Etanercept } \\
(\mathrm{n}=35,731)\end{array}$ & $\begin{array}{l}\text { Adalimumab } \\
(n=37,633)\end{array}$ & $\begin{array}{l}\text { Golimumab } \\
(\mathrm{n}=3625)\end{array}$ \\
\hline$\downarrow$ & $\downarrow$ & $\downarrow$ \\
\hline \multicolumn{3}{|c|}{$\begin{array}{l}\text { Include patients who had at least one non-rule-out diagnosis of } \\
\text { psoriatic arthritis (ICD-9-CM: 696.0) from the start date of } \\
\text { baseline period to the initiation date (inclusive) }\end{array}$} \\
\hline $\begin{array}{l}\text { Etanercept } \\
(\mathrm{n}=6272)\end{array}$ & $\begin{array}{l}\text { Adalimumab } \\
(n=5709)\end{array}$ & $\begin{array}{l}\text { Golimumab } \\
(\mathrm{n}=939)\end{array}$ \\
\hline$\downarrow$ & $\downarrow$ & $\downarrow$ \\
\hline \multicolumn{3}{|c|}{$\begin{array}{l}\text { Include patients who had at least one biologic of interest in the } \\
\text { look-forward period to be eligible for continuous treatment }\end{array}$} \\
\hline $\begin{array}{l}\text { Etanercept } \\
(\mathrm{n}=4143)\end{array}$ & $\begin{array}{l}\text { Adalimumab } \\
(\mathrm{n}=3542)\end{array}$ & $\begin{array}{l}\text { Golimumab } \\
(\mathrm{n}=474)\end{array}$ \\
\hline$\downarrow$ & $\downarrow$ & $\downarrow$ \\
\hline \multicolumn{3}{|c|}{$\begin{array}{l}\text { Exclude patients with non-rule-out diagnosis }{ }^{\mathrm{e}} \text { from the initiation } \\
\qquad \text { date to the end of follow-up period }\end{array}$} \\
\hline $\begin{array}{l}\text { Etanercept } \\
(\mathrm{n}=2846)\end{array}$ & $\begin{array}{l}\text { Adalimumab } \\
(n=2351)\end{array}$ & $\begin{array}{l}\text { Golimumab } \\
(n=285)\end{array}$ \\
\hline$\downarrow$ & $\downarrow$ & $\downarrow$ \\
\hline \multicolumn{3}{|c|}{$\begin{array}{l}\text { Exclude patients who switched to other biologics from the start dat } \\
\text { of baseline period to the end of look-forward period }\end{array}$} \\
\hline $\begin{array}{l}\text { Etanercept } \\
(n=2446)\end{array}$ & $\begin{array}{l}\text { Adalimumab } \\
(\mathrm{n}=1868)\end{array}$ & $\begin{array}{l}\text { Golimumab } \\
(n=118)\end{array}$ \\
\hline$\downarrow$ & $\downarrow$ & $\downarrow$ \\
\hline \multicolumn{3}{|c|}{ Excluded patients $<18$ years at initiation date } \\
\hline $\begin{array}{l}\text { Etanercept } \\
(\mathrm{n}=2430)\end{array}$ & $\begin{array}{l}\text { Adalimumab } \\
(\mathrm{n}=1860)\end{array}$ & $\begin{array}{l}\text { Golimumab } \\
(\mathrm{n}=118)\end{array}$ \\
\hline$\downarrow$ & $\downarrow$ & $\downarrow$ \\
\hline \multicolumn{3}{|c|}{$\begin{array}{c}\text { Exclude patients who did not have capitation but had zero payment } \\
\text { on biologic of interest from the initiation date } \\
\text { to the end of follow-up period }\end{array}$} \\
\hline $\begin{array}{l}\text { Etanercept } \\
(\mathrm{n}=2342)\end{array}$ & $\begin{array}{l}\text { Adalimumab } \\
(\mathrm{n}=1788)\end{array}$ & $\begin{array}{l}\text { Golimumab } \\
(n=115)\end{array}$ \\
\hline
\end{tabular}

adalimumab $28.1 \%$, and golimumab $33.0 \%$, respectively), hyperlipidemia (etanercept $22.7 \%$, adalimumab $20.2 \%$, and golimumab $18.3 \%$ ), and osteoporosis (etanercept $17.37 \%$, adalimumab $18.5 \%$, and golimumab $16.5 \%$ ) presented as the three most common PsA-related comorbidities (Table 1).
Fig. 1 Patient selection chart. ${ }^{\text {a }}$ First use of biologic of interest is the index event. ${ }^{b}$ Baseline period is defined as 365 days prior to the index date. ${ }^{\mathrm{c}}$ Follow-up period is defined as 365 days after the index date. dook-forward period is defined as 90 days after the end of the followup period. ${ }^{\mathrm{e}}$ Non-rule-out diagnoses were ankylosing spondylitis, rheumatoid arthritis, Crohn's disease, juvenile idiopathic arthritis, ulcerative colitis, uveitis, human immunodeficiency virus, cancer, and tuberculosis. Data source: MarketScan Commercial and Medicare Supplemental databases (http://truvenhealth.com/your-healthcare-focus/ analytic-research/marketscan-research-databases). ICD-9-CM International Classification of Disease, Ninth Revision, Clinical Modification

\section{Medication utilization patterns}

The mean (SD) number of days of on-label, above-label, and below-label and no use was observed for each of the treatment cohorts by above-label category. Mean (SD) number of days of on-label use (golimumab, 295 [77] days; etanercept, 273 [100] days; and adalimumab, 267 [109] days) and above-label use (golimumab, 12 [57] days; etanercept, 17 [60] days; and adalimumab, 35 [89] days) was reported. Below-label use was not reported for golimumab, whereas etanercept and adalimumab reported a mean (SD) of 4 (30) and 1 (12) days, respectively. The mean (SD) number of days with no use was reported for etanercept (71 [72] days), adalimumab (63 [65] days), and golimumab (59 [61] days), respectively. Proportion of days covered appeared to be consistent across each biologic and for each above-label cohort on average about 0.8 (SD 0.2) (Table 2).

Most of the patients in each cohort had minimal to no above-label use (<30 days): $90.4 \%$ (etanercept), $85.0 \%$ (adalimumab), and $95.7 \%$ (golimumab), respectively. About $6.0 \%$ of patients in the etanercept cohort, $5.4 \%$ of patients in the adalimumab cohort, and $1.7 \%$ of patients in the golimumab cohort had 30-179 days of above-label use. The highest above-label dosing category $(\geq 180$ days above-label use) was observed for $9.6 \%$ of adalimumab, $4.1 \%$ of etanercept, and $2.6 \%$ of golimumab cohort patients (Table 2).

\section{Total all-cause annual healthcare costs associated with above-label use}

In the 12-month follow-up period, total all-cause annual healthcare costs (in US dollars) were assessed for each biologic cohort by above-label category, and total healthcare costs at $<30$ days of above-label use for each cohort were as follows: etanercept $\$ 30,625$, adalimumab $\$ 31,620$, and golimumab $\$ 37,224$ ), 30-179 days (etanercept $\$ 35,602$, adalimumab $\$ 38,915$, and golimumab $\$ 64,349)$, and $\geq 180$ days (etanercept $\$ 55,349$, adalimumab $\$ 54,176$, and golimumab \$47,993). Longer above-label dosing duration with either etanercept or adalimumab was associated with significantly $(p<0.05)$ higher total all-cause healthcare costs, total PsA-specific healthcare costs, and total biologic costs 
Table 1 Baseline demographic characteristics by etanercept, adalimumab, and golimumab cohorts

\begin{tabular}{|c|c|c|c|}
\hline & Etanercept cohort $(n=2342)$ & Adalimumab cohort $(n=1788)$ & Golimumab cohort $(n=115)$ \\
\hline Age (years), mean (SD) & $50.7(10.9)$ & $49.5(11.3)$ & $48.8(12.6)$ \\
\hline \multicolumn{4}{|l|}{ Age group, $n(\%)$} \\
\hline $18-24$ & $30(1.3)$ & $48(2.7)$ & $6(5.2)$ \\
\hline $25-34$ & $145(6.2)$ & $127(7.1)$ & $8(7.0)$ \\
\hline $35-44$ & $463(19.8)$ & $396(22.1)$ & $24(20.9)$ \\
\hline $45-54$ & $831(35.5)$ & $558(31.2)$ & $37(32.2)$ \\
\hline $55-64$ & $694(29.6)$ & $555(31.0)$ & $34(29.6)$ \\
\hline $65+$ & $179(7.6)$ & $104(5.8)$ & $6(5.2)$ \\
\hline \multicolumn{4}{|l|}{ Gender, $n(\%)$} \\
\hline Female & $960(41.0)$ & $740(41.4)$ & $55(47.8)$ \\
\hline \multicolumn{4}{|l|}{ United States Geographic Region, $n(\%)$} \\
\hline Northeast & $416(17.8)$ & $243(13.6)$ & $19(16.5)$ \\
\hline North central & $612(26.1)$ & $430(24.0)$ & $28(24.3)$ \\
\hline South & $796(34.0)$ & $730(40.8)$ & $47(40.9)$ \\
\hline West & $500(21.3)$ & $367(20.5)$ & $18(15.7)$ \\
\hline Unknown & $18(0.8)$ & $18(1.0)$ & $3(2.6)$ \\
\hline \multicolumn{4}{|l|}{ Health insurance } \\
\hline FFS & $1900(81.1)$ & $1488(83.2)$ & $102(88.7)$ \\
\hline $\mathrm{HMO}$ and POS & $408(17.4)$ & $280(15.7)$ & $13(11.3)$ \\
\hline Unknown & $34(1.5)$ & $20(1.1)$ & $0(0.0)$ \\
\hline Medication burden, mean $(\mathrm{SD})^{\mathrm{a}}$ & $7.3(5.3)$ & $8.1(5.5)$ & $8.8(6.0)$ \\
\hline Biologic naive, $n(\%)^{\mathrm{b}}$ & $783(33.0)$ & $791(44.0)$ & $49(43.0)$ \\
\hline Biologic experienced, $n(\%)^{\mathrm{b}}$ & $1559(67.0)$ & $997(56.0)$ & $66(57.0)$ \\
\hline Elixhauser comorbidity score, mean (SD) & $1.0(1.2)$ & $1.1(1.4)$ & $1.2(1.3)$ \\
\hline PsA-related comorbidity, $n(\%)$ & $1752(74.8)$ & $1380(77.2)$ & $81(70.4)$ \\
\hline Hypertension & $672(28.7)$ & $502(28.1)$ & $38(33.0)$ \\
\hline Hyperlipidemia & $532(22.7)$ & $361(20.2)$ & $21(18.3)$ \\
\hline Osteoporosis & $406(17.3)$ & $330(18.5)$ & $19(16.5)$ \\
\hline Respiratory disease & $195(8.3)$ & $161(9.0)$ & $11(9.6)$ \\
\hline Autoimmune disease & $190(8.1)$ & $166(9.3)$ & $14(12.2)$ \\
\hline Depression & $108(4.6)$ & $74(4.1)$ & $4(3.5)$ \\
\hline Fibromyalgia & $107(4.6)$ & $100(5.6)$ & $6(5.2)$ \\
\hline Obesity & $101(4.3)$ & $94(5.3)$ & $5(4.3)$ \\
\hline Anxiety & $96(4.1)$ & $80(4.5)$ & $7(6.1)$ \\
\hline Cardiovascular disease & $80(3.4)$ & $55(3.1)$ & $5(4.3)$ \\
\hline Type 2 diabetes & $65(2.8)$ & $78(4.4)$ & $4(3.5)$ \\
\hline Liver disease & $34(1.5)$ & $25(1.4)$ & $1(0.9)$ \\
\hline Gastrointestinal disease & $16(0.7)$ & $20(1.1)$ & $0(0.0)$ \\
\hline Neurological disorder & $10(0.4)$ & $4(0.2)$ & $1(0.9)$ \\
\hline
\end{tabular}

FFS fee for service, $H M O$ health maintenance organization, $n$ number, \% percentage, $P S A$ psoriatic arthritis, $P O S$ point of service, $S D$ standard deviation ${ }^{a}$ By Universal System of Classification, excluding the biologics etanercept, adalimumab, and golimumab

${ }^{\mathrm{b}}$ Biologic experienced: previous biologic use; biologic naive: no prior biologic use in the 6 months before index date

(30-179 versus $<30$ days, $\geq 180$ versus $30-179$ days, and $\geq 180$ versus $<30$ days) (Table 3 ).

When compared to the prior year, the difference in mean all-cause healthcare costs in each cohort was as follows: etanercept $\$ 10,561$ ( $<30$ days), \$16,213 (30-179 days), and
$\$ 25,167$ ( $\geq 180$ days); adalimumab $\$ 13,446$ ( $<30$ days), $\$ 17,623$ (30-179 days), and $\$ 16,251$ ( $\geq 180$ days). Longer above-label dosing duration with etanercept was associated significantly $(p<0.01)$ with increased differences in total all-cause healthcare costs, total PsA-specific healthcare costs, 


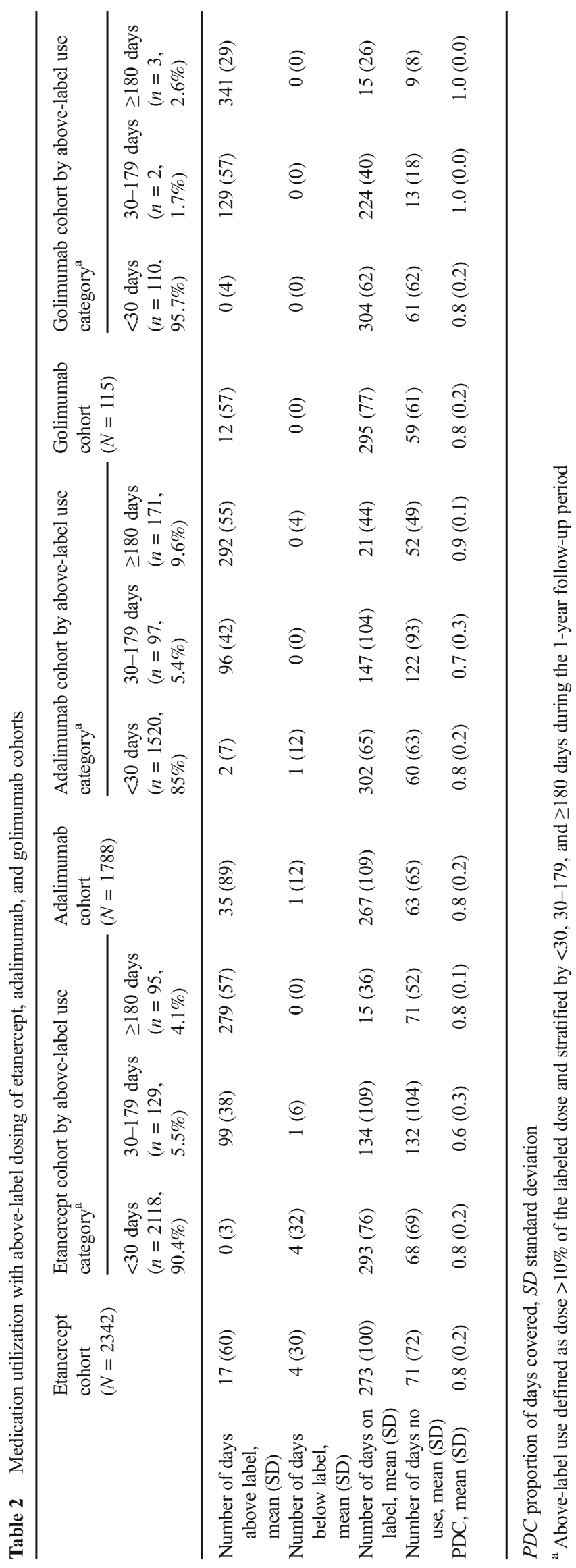




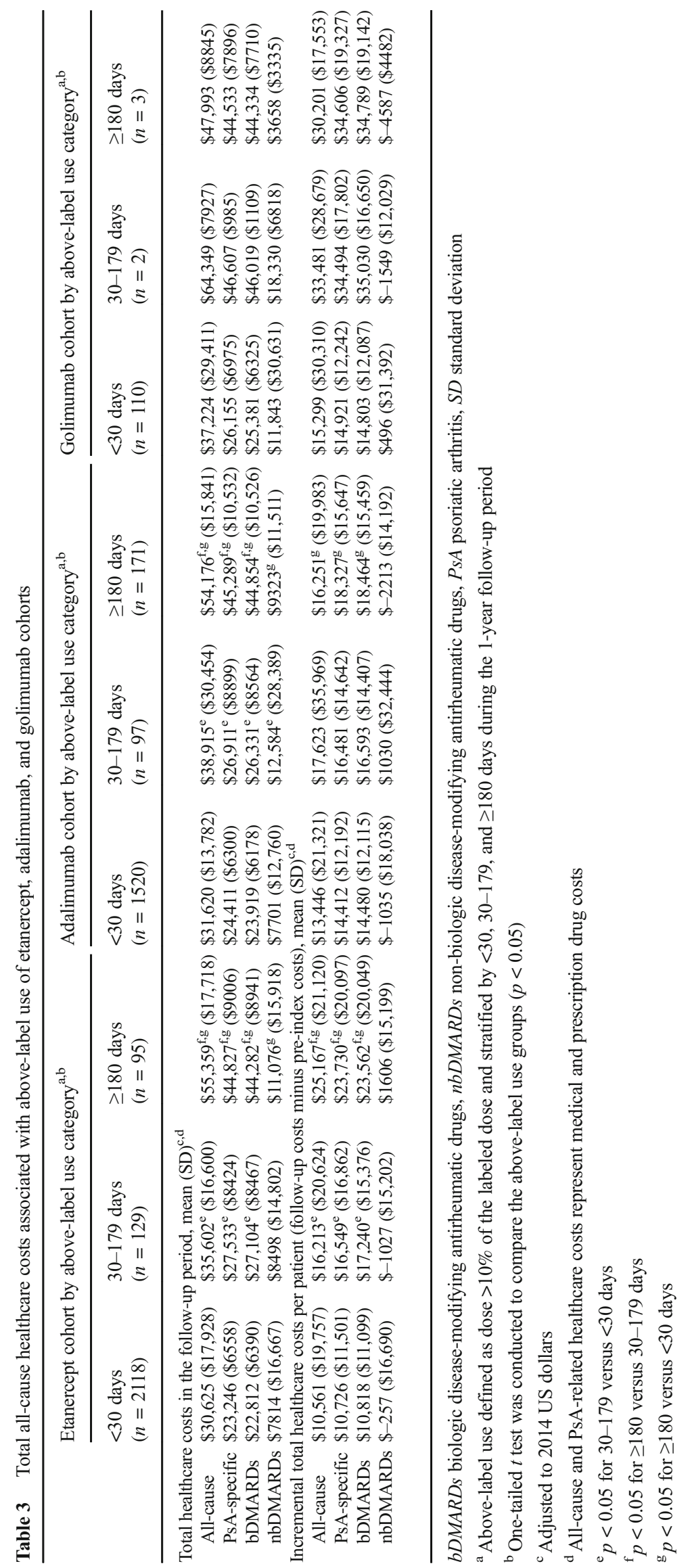


and total biologic costs ( $30-179$ versus $<30$ days, $\geq 180$ versus $30-179$ days, and $\geq 180$ versus $<30$ days). In addition, adalimumab was also associated with a significantly increased difference in PsA-specific healthcare and biologic costs for $\geq 180$ versus $<30$ days $(p<0.001)$ (Table 3 ).

For both analyses above, limited observations were available for the golimumab cohort due to the small sample size ( $<30$ days: golimumab $[n=110], 30-179$ days: golimumab $[n=2]$, and $\geq 180$ days: golimumab $[n=3]$ ), hence hindering the validity of data for statistical evaluation (Table 3 ).

\section{Discussion}

The current study is the first to describe medication utilization and the economic costs of above-label dosing of anti-TNF biologic therapy for patients with PsA in a real-world setting in the USA. Above-label dosing for 30-179 days was observed in approximately $6 \%$ of those receiving etanercept and adalimumab as well as $2 \%$ receiving golimumab. Clinically significant abovelabel dosing of $\geq 180$ days was observed for nearly double the patients receiving adalimumab than etanercept (10 versus $4 \%$, respectively). Furthermore, compared to etanercept, the mean number of days with above-label use was significantly higher for adalimumab and the mean number of days with belowlabel use was significantly lower in the etanercept group (both $p=0.01$ ). Studies in RA populations have also reported more frequent dose escalation among those taking adalimumab versus etanercept $[13,14,18-20]$, with two studies reporting a statistically significant difference $[13,20]$. This increased utilization in PsA could be due to the different doses used for adalimumab in RA (weekly or every other week approved) versus PsA (every other week) or the varying experience of the treating physician $[34,35]$.

In this study, higher mean annual total all-cause healthcare costs per patient were associated with increasing duration of above-label anti-TNF dosing (etanercept $\$ 30,625$ for $<30$ days versus $\$ 55,359$ for $\geq 180$ days; adalimumab $\$ 31,620$ for $<30$ days versus $\$ 54,176$ for $\geq 180$ days; golimumab $\$ 37,224$ for $<30$ days versus $\$ 47,993$ for $\geq 180$ days). For both etanercept and adalimumab, increased duration of above-label dosing (30-179 versus $<30$ days, $\geq 180$ versus $30-179$ days, and $\geq 180$ versus $<30$ days) was significantly associated with higher healthcare costs. Compared to the prior year, the difference in mean allcause healthcare costs increased in each cohort. Longer duration of above-label etanercept use was significantly associated with greater differences in healthcare costs $(30-179$ versus $<30$ days, $\geq 180$ versus $30-179$ days, and $\geq 180$ versus $<30$ days; all $p<0.01$ ), whereas in the adalimumab cohort, higher healthcare costs were only significant for the $\geq 180$ versus $<30$-day comparison $(p<0.05)$. Limited observations were available for the golimumab cohort due to the small sample size.
In the USA, the direct annual healthcare costs for PsA are estimated to be as high as $\$ 1.9$ billion. Indirect costs associated with PsA account for 52 to $72 \%$ of the total annual costs. Both direct and indirect costs associated with PsA increase with worsening physical function and disease activity [34]. Our study estimated that the total annual anti-TNF costs for those with less than 30 days of above-label dosing were approximately $\$ 22,812$ for etanercept, $\$ 23,919$ for adalimumab, and $\$ 25,381$ for golimumab. These findings are aligned with another US commercial claims database analysis, which reviewed anti-TNF biologic therapy across different indications and reported similar annual treatment costs as reported in this study for PsA across the anti-TNF biologics, etanercept $(\$ 26,916)$, golimumab $(\$ 27,987)$, and adalimumab $(\$ 28,749)$ [26]. The current study was the first to report that the total annual PsA, anti-TNF biologic-related, and PsA-specific healthcare costs significantly increased with the duration of above-label dosing. This study also evaluated the cost of non-biologic DMARDs which are often added to therapy and could have cost implications, especially patients with above-label use.

When dealing with a lack of treatment response, it is important to understand and consider the cost implications of off-label utilization in the real-world setting [8]. The current study is the first to provide an estimated total annual all-cause healthcare cost of $\$ 55,349$ (etanercept), $\$ 54,176$ (adalimumab), and $\$ 47,993$ (golimumab) US dollars for above-label use ( $\geq 180$ days) in PsA. The impact of these costs among patients with $\geq 180$ days of above-label use could equate to $\$ 2,040,885$ (etanercept), $\$ 3,345,444$ (adalimumab), and $\$ 45,012$ (golimumab), respectively. Similar cost estimates for above-label use of etanercept and adalimumab have been reported in a real-world population of RA patients, with a range of $\$ 20,000$ to $\$ 23,000$ US dollars $[13,14]$.

The economic impact of above-label prescribing should be taken into consideration along with the benefits and safety risks in clinical practice [17]. Therapy modifications may require an individualized approach to account for factors such as disease severity, quality of life, and comorbidities [17, 23]. In studies of PsO, dose escalation - primarily an increase in dosing frequency - is performed when patients fail to respond, or only partially respond, to the standard dose [17]. Indeed, dose escalation with etanercept (50 mg twice weekly) and adalimuab (40 mg weekly) has been associated with greater efficacy than standard dosing [17]. Among patients with rheumatoid arthritis, increased dosing frequency generally occurs 4-9 months after treatment initiation [37].

For patients with PsA, dose escalation may reflect a partial response to the standard treatment dose or a flare-up of symptoms or disease progression. Alternatively, it may suggest that physicians are unaware of the treatment guidelines for PsA, which recommend a switch in biologics for patients who do 
not achieve minimum disease activity after 3-6 months of treatment $[15,38]$. The guidelines do not discuss the practice of above-label dosing but do emphasize the importance of evaluating risks of treatment, with regard to overall safety and effects on comorbidities [15, 38]. An understanding of the reasons for above-label dosing and the impact on efficacy and safety of these regimens through further studies is critical for effective decision-making and care of patients with PsA.

This claims-based analysis study has limitations that should be noted. Patient information that may influence dose escalation such as disease severity and concurrent treatments for PsA were not captured, and reasons for above-label dosing were not available. Administrative claims data were not collected for research purposes, and diagnoses on claims may have been coded incorrectly or not coded at all, thereby potentially introducing measurement error with respect to ICD-9-CM-based variables. The current study was limited to individuals with commercial health coverage; therefore, findings may not be generalizable to people with Medicaid, Medicare, other insurance, or no insurance. Using a retrospective database approach limits the study to those who are clinically diagnosed and receive medications through their insurance. Since patients were not randomized to the different treatments, there may be some uncontrolled biases that could affect treatment outcomes. Provider bias for above-label dosing to control symptoms may also have influenced the utilization patterns observed among those receiving bDMARDs. Overall, these limitations are typical of any claims-based analysis and do not impede the conclusions drawn regarding the real-world utilization and costs associated with abovelabel doses of bDMARDs for patients with PsA in the USA.

\section{Conclusion}

In conclusion, this retrospective, real-world study from a large US claims database observed above-label dosing of almost all anti-TNFs approved for PsA, etanercept, adalimumab, and golimumab, with the exclusion of infliximab. Significantly higher healthcare costs per patient were associated with a longer duration of above-label dosing. Even minimal above-label doses of etanercept and adalimumab were shown to be associated with significantly increased healthcare costs. While the majority of patients in the study were observed with $<30$ days of above-label dosing, a subset of patient had dose escalation which may suggest an inadequacy of standard anti-TNF dosing regimens for PsA populations with prior biologic experience. More research to understand reasons for above-label prescribing in a real-world setting could aid physicians and decision makers in defining ideal treatment regimens.
Acknowledgments Write All, Inc. of Sonoma, CA, provided medical writing and editorial assistance for this manuscript.

\section{Compliance with ethical standards}

Conflict of interest Funding for this study was provided by Novartis Pharmaceuticals Corporation. S. Schwartzman works at the Hospital for Special Surgery, New York, NY, and is a consultant for Abbvie, Crescendo, Epirus, Genentech, Janssen, Novartis, Hospira, Pfizer, UCB, Discus Analytics, and the National Psoriasis Foundation. Y. Li and J.B. Palmer are employees of Novartis Pharmaceuticals Corporation. H. Zhou is an Analyst at KMK Consulting Inc. and works as a consultant for Novartis Pharmaceuticals Corporation.

Open Access This article is distributed under the terms of the Creative Commons Attribution 4.0 International License (http:// creativecommons.org/licenses/by/4.0/), which permits unrestricted use, distribution, and reproduction in any medium, provided you give appropriate credit to the original author(s) and the source, provide a link to the Creative Commons license, and indicate if changes were made.

\section{References}

1. Lubrano E, Spadaro A (2014) Pharmacoeconomic burden in the treatment of psoriatic arthritis: from systematic reviews to real clinical practice studies. BMC Musculoskelet Disord 15:25

2. Cawson MR, Mitchell SA, Knight C, Wildey H, Spurden D, Bird A et al (2014) Systematic review, network meta-analysis and economic evaluation of biological therapy for the management of active psoriatic arthritis. BMC Musculoskelet Disord 15:26

3. American Academy of Dermatology Working Group, Menter A, Korman NJ, Elmets CA, Feldman SR, Gelfand JM et al (2011) Guidelines of care for the management of psoriasis and psoriatic arthritis: section 6. Guidelines of care for the treatment of psoriasis and psoriatic arthritis: case-based presentations and evidence-based conclusions. J Am Acad Dermatol 65:137-174

4. Day MS, Nam D, Goodman S, Su EP, Figgie M (2012) Psoriatic arthritis. J Am Acad Orthop Surg 20:28-37

5. Ogdie-Beatty AR. GRAPPA initiatives continue to chart the way for psoriasis, psoriatic arthritis. PM360-Rheumatology. Available from: http:/www.pm360online.com/grappa-initiatives-continueto-chart-the-way-for-psoriasis-psoriatic-arthritis/. Internet. Accessed 30 June 2015

6. Coates LC, Ritchlin CT, Kavanaugh AF (2014) GRAPPA treatment recommendations: an update from the GRAPPA 2013 Annual Meeting. J Rheumatol 41:1237-1239

7. Nash P, Lubrano E, Cauli A, Taylor WJ, Olivieri I, Gladman DD (2014) Updated guidelines for the management of axial disease in psoriatic arthritis. J Rheumatol 41:2286-2289

8. Puig L (2014) Treatment of moderate to severe plaque psoriasis with biologics: analysis of the additional cost of temporary dose escalation vs switch to another biologic after failure of maintenance therapy. Actas Dermosifiliogr 105:401-412

9. Coates LC (2015) Treating to target in psoriatic arthritis. Curr Opin Rheumatol 27:107-110

10. Zhang W, Islam N, Ma C, Anis AH (2015) Systematic review of cost-effectiveness analyses of treatments for psoriasis. PharmacoEconomics 33:327-340

11. Coates LC, Moverley AR, McParland L, Brown S, Navarro-Coy N, O'Dwyer JL et al (2015) Effect of tight control of inflammation in 
early psoriatic arthritis (TICOPA): a UK multicentre, open-label, randomised controlled trial. Lancet 386:2489-2498

12. Martinez-Cutillas J, Alerany-Pardo C, Borrás-Blasco J, BrotoSumalla A, Burgos-SanJosé A, Climent-Bolta C et al (2015) The use of adalimumab, etanercept, golimumab and infliximab in rheumatic pathologies: variation between label dosage and real-world use. Expert Rev Pharmacoecon Outcomes Res 15:851-858

13. Joyce AT, Gandra SR, Fox KM, Smith TW, Pill MW (2014) National and regional dose escalation and cost of tumor necrosis factor blocker therapy in biologic-naive rheumatoid arthritis patients in US health plans. J Med Econ 17:1-10

14. Moots RJ, Mays R, Stephens J, Tarallo M (2015) Burden of dose escalation with tumour necrosis factor inhibitors in rheumatoid arthritis: a systematic review of frequency and costs. Clin Exp Rheumatol 33:737-745

15. Gossec L, Smolen JS, Gaujoux-Viala C, Ash Z, Marzo-Ortega H, van der Heijde D et al (2012) European League Against Rheumatism recommendations for the management of psoriatic arthritis with pharmacological therapies. Ann Rheum Dis 71:4-12

16. Ritchlin CT, Kavanaugh A, Gladman DD, Mease PJ, Helliwell P, Boehncke WH et al (2009) Treatment recommendations for psoriatic arthritis. Ann Rheum Dis 68:1387-1394

17. Brezinski EA, Armstrong AW (2012) Off-label biologic regimens in psoriasis: a systematic review of efficacy and safety of dose escalation, reduction, and interrupted biologic therapy. PLoS One $7:$ :e33486

18. Wu E, Chen L, Birnbaum H, Yang E, Cifaldi M (2008) Retrospective claims data analysis of dosage adjustment patterns of TNF antagonists among patients with rheumatoid arthritis. Curr Med Res Opin 24:2229-2240

19. Huang X, Gu NY, Fox KM, Harrison DJ, Globe D (2010) Comparison of methods for measuring dose escalation of the subcutaneous TNF antagonists for rheumatoid arthritis patients treated in routine clinical practice. Curr Med Res Opin 26:1637-1645

20. Ollendorf DA, Klingman D, Hazard E, Ray S (2009) Differences in annual medication costs and rates of dosage increase between tumor necrosis factor-antagonist therapies for rheumatoid arthritis in a managed care population. Clin Ther 31:825-835

21. Harrison DJ, Huang X, Globe D (2010) Dosing patterns and costs of tumor necrosis factor inhibitor use for rheumatoid arthritis. Am J Health Syst Pharm 67:1281-1287

22. Bonafede M, Joseph GJ, Princic N, Harrison DJ (2013) Annual acquisition and administration cost of biologic response modifiers per patient with rheumatoid arthritis, psoriasis, psoriatic arthritis, or ankylosing spondylitis. J Med Econ 16:1120-1128

23. Feldman SR, Zhao Y, Navaratnam P, Friedman HS, Lu J, Tran MH (2015) Patterns of medication utilization and costs associated with the use of etanercept, adalimumab, and ustekinumab in the management of moderate-to-severe psoriasis. J Manag Care Spec Pharm 21:201-209

24. Olivieri I, de Portu S, Salvarani C, Cauli A, Lubrano E, Spadaro A et al (2008) The psoriatic arthritis cost evaluation study: a cost-ofillness study on tumour necrosis factor inhibitors in psoriatic arthritis patients with inadequate response to conventional therapy. Rheumatology (Oxford) 47:1664-1670
25. Rodgers M, Epstein D, Bojke L, Yang H, Craig D, Fonseca T et al (2011) Etanercept, infliximab and adalimumab for the treatment of psoriatic arthritis: a systematic review and economic evaluation. Health Technol Assess 15:i-xxi 1-329

26. Chastek B, White J, Van Voorhis D, Tang D, Stolshek BS (2016) A retrospective cohort study comparing utilization and costs of biologic therapies and JAK inhibitor therapy across four common inflammatory indications in adult US managed care patients. Adv Ther 33:626-642

27. Greenberg JD, Palmer JB, Li Y, Herrera V, Tsang Y, Liao M (2016) Healthcare resource use and direct costs in patients with ankylosing spondylitis and psoriatic arthritis in a large US cohort. J Rheumatol 43:88-96

28. Howe A, Eyck LT, Dufour R, Shah N, Harrison DJ (2014) Treatment patterns and annual drug costs of biologic therapies across indications from the Humana commercial database. J Manag Care Spec Pharm 20:1236-1244

29. Truven Health Analytics MarketScan Resarch Databases. Truven Health Analytics Inc. Ann Arbor, MI. Available from: http:// truvenhealth.com/your_healthcare_focus/research/marketscan research_databases.aspx. Internet. Accessed 15 June 2016

30. Danielson E Health research data for the real world: the MarketScan ${ }^{\circledR}$ databases (White Paper). Ann Arbor, MI Truven Health Analytics Inc.; 2014Contract

31. Elixhauser A, Steiner C, Harris DR, Coffey RM (1998) Comorbidity measures for use with administrative data. Med Care 36:8-27

32. Quan H, Sundararajan V, Halfon P, Fong A, Burnand B, Luthi JC et al (2005) Coding algorithms for defining comorbidities in ICD-9CM and ICD-10 administrative data. Med Care 43:1130-1139

33. Chronic Conditions Data Warehouse. Condition categories. Available from: http://www.ccwdata.org/web/guest/conditioncategories. Internet. Accessed 7 May 2016

34. Lee S, Mendelsohn A, Sarnes E (2010) The burden of psoriatic arthritis: a literature review from a global health systems perspective. P T 35:680-689

35. Zaour N BM, Liu N, Borrelli R, Fischer A (2015) The cost of hospitalization and length of stay for chronic heart failure cases in Canada [abstract]. Presented at: 2015 Canadian Cardiovascular Congress; Toronto, ON; Can J Cardiol 31(10):S273

36. Flynn KE, Lin L, Ellis SJ, Russell SD, Spertus JA, Whellan DJ et al (2009) Outcomes, health policy, and managed care: relationships between patient-reported outcome measures and clinical measures in outpatients with heart failure. Am Heart J 158:S64-S71

37. Ariza-Ariza R, Navarro-Sarabia F, Hernandez-Cruz B, RodriguezArboleya L, Navarro-Compan V, Toyos J (2007) Dose escalation of the anti-TNF-alpha agents in patients with rheumatoid arthritis. A systematic review. Rheumatology (Oxford) 46:529-532

38. Gottlieb A, Korman NJ, Gordon KB, Feldman SR, Lebwohl M, Koo JY et al (2008) Guidelines of care for the management of psoriasis and psoriatic arthritis: section 2. Psoriatic arthritis: overview and guidelines of care for treatment with an emphasis on the biologics. J Am Acad Dermatol 58:851-864 